\title{
PERCEPÇÃO DO ACOMPANHANTE DO PACIENTE PEDIÁTRICO DURANTE A INDUÇÃO E O DESPERTAR DA ANESTESIA
}

\section{Perception of the pediatric patient accompany during anesthesia induction and awakening}

\section{Percepción del acompañante del paciente pediátrico durante la inducción y el despertar de la anestesia}

\author{
Sabrina Binkowski', Gisele Pereira de Carvalho², Rita Catalina Aquino Caregnato ${ }^{2 *}$
}

RESUMO: Objetivo: Conhecer as percepções de acompanhantes das crianças na indução anestésica e no despertar da anestesia. Método: Estudo exploratório, descritivo, qualitativo, realizado em um centro cirúrgico (CC) de um hospital pediátrico de Porto Alegre, Rio Grande do Sul, Brasil, com sete mães presentes na indução anestésica e no despertar da criança da anestesia. A coleta de dados foi realizada em duas fases: 1. observação não participativa na pré-indução e na indução anestésica; 2. entrevista semiestruturada na sala de recuperação pós-anestésica (SRPA). Resultados: Da análise de conteúdo dos diários de campo emergiram duas categorias: estratégias utilizadas pelos acompanhantes e tranquilidade. As estratégias usadas foram: choro, amor e carinho. Das entrevistas emergiram duas categorias: experiência positiva e experiência negativa, sendo a primeira a mais destacada. Conclusão: Acompanhar o filho no processo anestésico-cirúrgico desencadeou mais percepções positivas do que negativas nas mães. Além de dar suporte e tranquilidade à criança, as acompanhantes se sentiram mais seguras. Palavras-chave: Anestesia. Enfermagem de centro cirúrgico. Criança. Mães. Pediatria.

ABSTRACT: Objective: To know the perceptions o children's companion in anesthetic induction and awakening. Method: An exploratory, descriptive, qualitative study carried out in the surgical center (SC) of a pediatric hospital in Porto Alegre, Rio Grande do Sul, Brazil, with seven mothers present during anesthetic induction and awakening of the child. Data collection was carried out in two parts: 1 . Non-participatory observation in anesthetic pre-induction and induction; 2. Semi structured interview in the post-anesthetic recovery room (PARR). Results: Two categories emerged from the contents analysis of field journals: strategies used by companions and tranquility. The strategies used were: crying, love and affection. Two categories emerged from the interviews: positive and negative experiences, the former being the most outstanding one. Conclusion: Accompanying a child in the anesthetic-surgical process triggered more positive than negative impressions on mothers. In addition to giving support and tranquility to the child, companions themselves would feel safer. Keywords: Anesthesia. Operating Room Nursing. Child. Mothers. Pediatrics.

RESUMEN: Objetivo: Conocer las percepciones de acompañantes de los niños en la inducción anestésica y en el despertar de la anestesia. Método: Estudio exploratorio, descriptivo y cualitativo, realizado en un centro quirúrgico (CQ) de un hospital pediátrico de Porto Alegre, Rio Grande do Sul, Brasil, con siete madres presentes em la inducción anestésica y el despertar del niño de la anestesia. La recolección de datos fue realizada em dos fases: 1. Observación no participativa em la pre-inducción y en la inducción anestésica; 2. Entrevista semiestructurada en la sala de recuperación postanestésica (SRPA). Resultados: Dos categorías surgieron del análisis del contenido de los diarios de campo: estrategias utilizadas por los acompañantes y tranquilidad. Las estrategias usadas fueron: llanto, amor y afecto. Dos categorías surgieron de las entrevistas: experiencia positiva y experiencia negativa, siendo la primera la más destacada. Conclusión: Acompañar a niños en el proceso anestésico-quirúrgico desencadenó más percepciones positivas que negativas em las madres. Además de dar suporto y tranquilidad al niño, las acompañantes se sintieron más seguras.

Palabras clave: Anestesia. Enfermería de Quirófano. Niño. Madres. Pediatría.

'Estudante de Enfermagem, Universidade Federal de Ciências da Saúde de Porto Alegre (UFCSPA) - Porto Alegre (RS), Brasil.

2Doutora; Enfermeira, UFCSPA - Porto Alegre (RS), Brasil.

*Autor correspondente: ritac.ufcspa@gmail.com

Recebido: 18/10/2017 - Aprovado: 03/12/2017

DOI: 10.5327/Z1414-4425201800010004 


\section{INTRODUÇÃO}

A cirurgia, assim como a internação hospitalar, é uma experiência que traz muita ansiedade às crianças e aos seus acompanhantes, provoca mudança na rotina de toda a família e gera diversos sentimentos, como estresse, ao afastá-la do convívio familiar e social com o qual está acostumada. No centro cirúrgico (CC), essa situação geralmente é potencializada, uma vez que se trata de um ambiente fechado e diferente, onde o acesso é restrito e as pessoas se vestem com uniformes iguais ${ }^{1}$.

Nesse contexto, é importante levar em consideração o significado de percepção e de sentimentos. Entende-se "percepção" no sentido de um "[...] processo pelo qual a natureza e o significado dos estímulos sensoriais são reconhecidos e interpretados" ; a palavra "sentimentos" é entendida como sinônimo de "emoções", ou seja, "[...] estados afetivos que podem ser experimentados e que têm a propriedade de excitar e motivar o indivíduo" 2 .

A ansiedade pode se manifestar de formas diferentes nos pacientes pediátricos, conforme as faixas etárias e de acordo com o grau de desenvolvimento. Quanto maior o grau de ansiedade da criança no pré-operatório, maior a chance de ela apresentar distúrbios no pós-operatório, principalmente relacionados ao comportamento (como pesadelos, irritabilidade, problemas na alimentação e desobediência) ${ }^{3}$.

Nesse sentido, a Lei no 8.069 de 1990, do Estatuto da Criança e do Adolescente, no artigo 12, contempla que: "os estabelecimentos de atendimento à saúde deverão proporcionar condições para a permanência em tempo integral de um dos pais ou responsável, nos casos de internação de criança ou adolescente" 4 .

A presença do familiar durante a indução anestésica pode diminuir a ansiedade da criança, o que diminui a necessidade de restrição física e melhora a relação enfermeiro-paciente. Contudo, existe ainda uma resistência quanto à presença dos pais nesse momento, atitude esta oriunda dos valores que se mantêm arraigados na área da saúde 5 .

A indução anestésica do paciente pediátrico é um momento gerador de grande desconforto, tanto para ele quanto para o seu acompanhante. A criança pequena muitas vezes não entende o que está acontecendo, e pode relacionar o momento de internação e da realização de um procedimento cirúrgico a uma punição. Isso causa prejuízos à sua recuperação, pois vivenciar situações desagradáveis influencia no pós-operatório imediato e pode trazer algumas lembranças negativas, que permanecem por anos ${ }^{6}$.
Nesse contexto, emergiu como questão de pesquisa a ser investigada: quais as percepções suscitadas em acompanhantes de crianças na indução anestésica e no despertar da anestesia de cirurgias pediátricas?

Justifica-se esta pesquisa devido à carência de estudos que abordem o tema de acompanhantes de pacientes pediátricos durante o processo anestésico.

\section{OBJETIVOS}

1. Conhecer as percepções dos acompanhantes de crianças na indução anestésica e no despertar da anestesia.

2. Identificar os sentimentos suscitados e as estratégias utilizadas pelos acompanhantes que participaram da indução anestésica e acompanharam o despertar da criança da anestesia.

\section{MÉTODO}

Trata-se de um estudo exploratório, descritivo, com abordagem qualitativa, seguindo a fundamentação teórica da análise de conteúdo de Bardin, com categorização temática, que permite o entendimento e a descrição do fenômeno investigado, fundamentado nas falas dos acompanhantes ${ }^{7}$.

A pesquisa foi realizada em um CC de um hospital pediátrico, localizado em Porto Alegre, Rio Grande do Sul, Brasil.

A população escolhida para este estudo foram os acompanhantes de crianças submetidas a procedimentos cirúrgicos. Os critérios de inclusão foram: ser acompanhante (familiar ou representante legal) de crianças submetidas a procedimentos cirúrgicos, que estivessem presentes na indução anestésica e no despertar da anestesia. Considerou-se como critérios de exclusão:

1. acompanhantes que não estiveram presentes nas duas fases de coleta de dados;

2. acompanhantes de crianças que realizaram procedimentos cirúrgicos com anestesia local ou anestesia regional ou cirurgias de grande porte, visto que esses pacientes geralmente não vão para a sala de recuperação pós-anestésica (SRPA) após a cirurgia.

A amostra foi constituída por sete mães que atenderam os critérios de inclusão. O número de sujeitos incluídos no presente estudo foi determinado pela saturação dos dados, visto se tratar de uma pesquisa qualitativa. 
A coleta de dados ocorreu durante os meses de maio e julho de 2017, nos turnos manhã e tarde. As acompanhantes foram convidadas a participar da pesquisa conforme ordem de chegada na sala de pré-indução, local onde as crianças e as mães aguardavam para entrar na sala de cirurgia. Foi explicado sobre o estudo e, às que aceitavam participar, foi entregue o termo de consentimento livre e esclarecido (TCLE) para posterior coleta de dados.

O levantamento de informações foi realizado em duas fases. A primeira foi a observação não participativa na pré-indução e na indução anestésica, na qual o participante estava junto à criança, cujas experiências observadas e reflexões da pesquisadora foram registradas em um diário de campo para cada sujeito da pesquisa, totalizando sete diários. O instrumento foi identificado como diário de campo do entrevistado, apresentado no decorrer do texto como DCE, seguido do número sequencial de identificação do entrevistado.

A segunda fase ocorreu na SRPA, após a criança ter despertado da anestesia. Nesse momento, foi realizada uma entrevista semiestruturada, utilizando um roteiro com questões norteadoras, que buscaram responder os objetivos do estudo. Isso foi gravado e, posteriormente, transcrito, ocorrendo na beira do leito da criança na SRPA. Foram feitas três perguntas, a saber:

1. "Conte-me como foi o despertar da criança da anestesia".

2. "Qual foi o seu sentimento ao ver a criança acordando?".

3. "Agora que o procedimento cirúrgico já está finalizado e você está ao lado da criança, conte-me como foi ter a oportunidade de estar ao lado dela durante a indução anestésica”.

As informações foram analisadas por categorização temática, conforme Bardin 7 . O software NVivo $®$ foi utilizado para realizar os recortes dos registros mais importantes dos diários e das entrevistas.

O presente projeto foi encaminhado via Plataforma Brasil aos Comitês de Ética e Pesquisa (CEP) das instituições proponente e coparticipante, a fim de obter a autorização para sua execução. A coleta de dados ocorreu somente após as devidas aprovações (CAAE número 62523016.0.0000.5683 e CAAE número 62523016.0.3001.5345). Para tanto, foram seguidas as normas da Resolução no $466 / 2012^{8}$, que dispõe sobre as diretrizes e normas de pesquisas envolvendo seres humanos. Os sujeitos selecionados para a participação na pesquisa foram esclarecidos sobre a finalidade da mesma e assinaram o TCLE, podendo descontinuar sua participação no estudo, se desejassem, sem prejuízo algum.
A fim de que o anonimato dos participantes seja garantido, as iniciais dos nomes foram codificadas pela letra E (entrevistado) maiúscula, seguida de número sequencial $(1,2,3 \ldots)$, de acordo com a ordem de participação no estudo.

\section{RESULTADOS}

Participaram da pesquisa 7 mães de crianças com idades entre 2 e 11 anos, submetidas à anestesia geral combinada.

Da análise de conteúdo dos diários de campo da pesquisadora emergiram duas categorias: tranquilidade e estratégias utilizadas pelos acompanhantes. A primeira apareceu em todos os registros dos diários de campo. A segunda foi constatada em cinco unidades de registro $(71,42 \%)$.

Observou-se que cinco mães manifestaram, como estratégia, choro no momento da indução anestésica de seus filhos. Outras estratégias também foram demonstradas, como dar amor e carinho, além do papel da circulante de sala, conforme recortes apresentados a seguir:

1. DCE5 - [...] Ao dormir, a anestesista disse para a mãe que a criança já havia dormido [...] A mãe a beijou e saiu chorando. A circulante a acompanhou até a saída, perguntou se estava tudo bem e explicou que ela poderia descer, tomar um café, que a chamariam quando acabasse a cirurgia.

2. DCE7 - Pré-indução: Mãe bem tranquila [...] o filho brincando muito com os brinquedos e com as crianças na sala de indução. Bem agitado [...]. Indução anestésica: Mãe aparentemente bem tranquila. Criança deitou na cama de cirurgia sozinha. Equipes de anestesiologia e de enfermagem bem comunicativas com a mãe e com a criança [...]. Logo a criança dormiu [...]. Ao beijar a criança na testa, a mãe começou a chorar. A circulante acompanhou a mãe até a saída [...] disse que ela poderia ir tomar um café e comer alguma coisa, pois demoraria [...] para a cirurgia acabar e que assim que a criança fosse para a sala de recuperação a chamariam lá.

A tranquilidade surgiu em todos os registros dos diários de campo, tanto nas crianças quanto nas mães, conforme recortes apresentados:

1. DCE2 - Na sala de pré-indução, a criança estava brincando muito com os brinquedos e a mãe estava muito tranquila [...]. Na sala de cirurgia, a equipe foi conversando com a mãe [...]. A mãe e a criança estavam 
muito tranquilas [...]. Após a criança adormecer, a mãe deu um beijo na testa dela e a circulante da sala a acompanhou até a sala de espera e explicou o tempo de demora, que poderia descer para tomar um café e que assim que a criança fosse para a sala de recuperação a chamariam.

2. DCE4 - Na sala de pré-indução: mãe bem tranquila, criança brincando com os brinquedos. Durante a indução: mãe aparentemente tranquila, criança também. A indução foi muito rápida [...]. Logo que a criança adormeceu, a mãe saiu chorando, sem alguém da equipe a acompanhando.

Da análise de conteúdo das entrevistas surgiram duas categorias temáticas, a saber: experiência positiva e experiência negativa. A primeira constou em seis unidades de registro e, a segunda, em apenas um registro.

Expressões de felicidade e alívio como sendo representativas de sentimentos positivos surgiram nas falas de seis mães $(85,7 \%)$. Apenas uma (14,3\%) participante informou que estar presente no momento da indução anestésica trouxe sentimentos difíceis de enfrentar, tornando essa oportunidade uma experiência negativa, conforme disse:

1. E1 - É porque, assim, é a primeira vez dela, então eu não sabia como ela ia reagir [...]. Bah, eu fiquei muito... nervosa, sei lá... sensação muito ruim... tipo, ela sozinha lá [...].

2. E1 -(risos) Não é uma experiência muito boa... Porque é uma sensação muito de não saber o que te espera ali na hora, né... Como é que vai reagir [...] eu não gostei muito (risos) [...]. Eu estava... Assim, louca perguntando ali pra ver se ela estava bem... Não sabe o que... O que acontece lá dentro depois que tu sai, né [...]. Eu, pelo menos, fiquei com medo, né, sabe... De achar que deu [...] alguma complicação, né [...]. Lá dentro eu me senti muito mal [...]. Agora eu estou mais tranquila.

Mesmo que tenham ocorrido sentimentos difíceis, as mães relataram que ter participado de todo o processo anestésicocirúrgico foi uma experiência positiva, conforme ilustram em suas falas:

1. E3-Ai, estava meio... meio nervosa. Fiquei um pouco nervosa, mais com ver ela daquele jeito [...]. Ai, fico feliz [...]. Agora há pouco o pai dela ligou [...] falei com ele que tá tudo bem [...]. Ai, foi bom, para gente acompanhar, né... E dá mais uma... Credibilidade para ela, ela fica mais tranquila, né? [...]. Foi melhor estar junto [...]. É muito melhor.

2. E4-Ai, de alívio (risos) [...]. Estava tensa [...] nervosa, porque... a gente sabe, né, que a anestesia geral ela é assustadora pelo nome ser geral (risos) [...]. Foi... Tudo, né... Tanto para mim, quanto para ele. Para eu ficar tranquila e ele também.

3. E6-Ai, de alívio [...]. Melhor impossível, porque a gente... Vê que ele tá sendo bem cuidado, né... A gente não fica com aquela dúvida de como é que será que ele tá [...]. Bem melhor assim [...] teria ficado muito nervosa.

4. E7 - Ai, foi ótimo [...]. Quando eu entrei aqui, eu me lembrei de quando ele nasceu... Então... Me deu um choque, sabe? [...]. Mas ele tá bem, graças a Deus [...]. Eu preferiria ter participado de tudo, até da cirurgia [...]. Claro que... Eu tive... Segurança, né [...] mas é filho da gente, né? Então, a gente... Não consegue... Tu sair e ir num lugar... E deixar, né? [...].

Quando questionadas sobre o despertar da criança da anestesia, surgiram expressões que remetiam tranquilidade, como é possível verificar nas falas a seguir:

1. E1 - É a primeira vez, né... Eu, né, não sabia como ela ia reagir, mas ela acordou muito calma.

2. E4 - Não, ele acordou tranquilo... Ele me olhou, ainda sonolento, estava calmo.

3. E7 - Não, foi calmo, foi calmo...

De acordo com os resultados obtidos no presente estudo, é possível verificar que, apesar de as mães aparentarem estar tranquilas durante a pré-indução e a indução anestésica, elas relataram ter sentimentos difíceis durante esses momentos, mas que prevaleceram a vontade e o benefício de estar junto dos filhos no momento do processo anestésico-cirúrgico sobre o fato de ter os sentimentos negativos. O choro, estratégia manifestada na indução anestésica, expressou os sentimentos de algumas mães na situação mencionada.

A tranquilidade, fato que foi observado nos períodos de pré-indução e na indução anestésica, foi relatada pelas mães na SRA. Além disso, elas descreveram sentimentos positivos no momento do despertar da criança da anestesia.

\section{DISCUSSÃO}

A presente pesquisa direcionou seu olhar aos acompanhantes das crianças que seriam operadas, evidenciando que, 
em todos os casos, foram as mães que acompanharam seus filhos. Em estudo realizado em São Paulo, as mães também foram a grande maioria dos acompanhantes de pacientes pediátricos que seguiram os procedimentos cirúrgicos e acabavam realizando o jejum junto com os filhos ${ }^{9}$. Esse dado foi semelhante ao encontrado nesta pesquisa, pois se verificou nos registros dos diários de campo que a circulante de sala geralmente falava para a mãe ir até a cafeteria comer alguma coisa ou tomar um café. Possivelmente, os profissionais fazem isso como rotina, porque geralmente a mãe também não se alimenta, visto que seu filho deve ficar sem "nada por via oral" (NPO) no período pré-operatório imediato.

Na pesquisa citada anteriormente ${ }^{9}$, houve manifestações de sentimentos como nervosismo, ansiedade e preocupação por parte das genitoras. Nesta pesquisa, a manifestação do choro foi presenciada em cinco das sete mães no período da indução anestésica. Apesar de algumas se mostrarem "ansiosas" (DCE1), "apreensivas" (DCE3) e "chorosas" (DCE5) no período de pré-indução, exteriorizaram calma durante a indução, até o momento em que a criança adormeceu.

Em outro estudo, os sentimentos dos acompanhantes das crianças em cirurgias pediátricas foram expressos por ansiedade, nervosismo e medo. Isso acontece no momento em que há a separação da criança, quando ela é encaminhada para a sala de cirurgia, e quem está acompanhando precisa ficar na sala de espera, imaginando o que pode estar acontecendo durante a intervenção ${ }^{10}$.

Além disso, as mães apresentaram diferentes manifestações de medo e ansiedade, por meio de choro ou de agitação, provocadas pelo desconhecido e relacionadas à cirurgia em si. Mesmo possuindo auxílio dos profissionais de saúde e informações a respeito do processo cirúrgico, diversos acompanhantes não foram capazes de ficar completamente tranquilos ${ }^{10}$.

Os resultados do presente estudo mostraram que, quando as mães acompanharam os filhos até a sala de cirurgia, aparentavam estar tranquilas; mas, após presenciar a perda da consciência do seu filho, choraram - evidenciando os mesmos sentimentos emergidos nos acompanhantes do estudo anteriormente citado $^{10}$.

Por mais que os acompanhantes tentem se manter calmos diante da situação de hospitalização, o desconhecimento do que pode ocorrer faz com que se sintam muito angustiados. As estratégias mais utilizadas pelos pais são: dar amor e carinho, procurar tranquilidade e buscar amparo espiritual $^{11}$. Os resultados do presente estudo vêm ao encontro do que foi relatado pelas autoras, visto que a maioria das mães demonstrou esse sentimento, beijando o filho após a indução anestésica. Apesar de a espiritualidade não ter sido observada nas manifestações das mães na presente pesquisa, não é improvável que tenham utilizado essa estratégia.

Nos registros dos diários de campo, evidenciou-se que os pacientes, em sua maioria, estavam calmos, fato importante porque a indução anestésica, por vezes, pode ser vista pela criança como uma punição por algo que fez $z^{6}$. Por esse motivo, às vezes se torna necessário preparar os pais, em um momento anterior, para introduzir a criança no ambiente de um CC.

A impossibilidade de participar ativamente, ou seja, apenas olhar e estar junto, pode, algumas vezes, ocasionar sentimentos negativos. Em alguns casos, ver o filho em situação de estresse, quando não se está no comando da situação, pode causar grande ansiedade em algumas genitoras. Os sentimentos de medo, ansiedade e nervosismo são provocados pelo desconhecido, por não se saber como vai acontecer o processo de indução anestésica, como a criança irá reagir e como ficará durante o período em que o acompanhante não poderá estar presente. Nesse contexto, a presença dos pais durante a indução anestésica aumenta consideravelmente a sua satisfação, fato que contribui para tornar a experiência positiva ${ }^{12}$.

Um estudo analisou a experiência de utilizar voluntários para acompanhar os pais até a sala de cirurgia, auxiliando-os e esclarecendo-os sobre o processo. Antes da cirurgia eletiva da criança, os pais receberam um panfleto contendo informações sobre a sua presença na indução anestésica. Dos pais que participaram desse processo, $99 \%$ referiram se sentir bem preparados para o procedimento ${ }^{13}$. Da mesma forma, nesta pesquisa a maioria das mães relatou que estar junto dos filhos nesse momento foi uma experiência positiva.

A presença dos pais durante o procedimento melhora a qualidade da indução anestésica nas crianças que não foram medicadas no pré-operatório, aumentando, assim, a ocorrência de induções mais suaves; ainda, ocorre menor necessidade de restrição física ${ }^{14}$. Nesta investigação, as induções anestésicas foram tranquilas, assim como o despertar da criança da anestesia. Ocorreu apenas uma situação em que foi necessário realizar uma espécie de contenção física, em que a mãe e a circulante de sala tiveram que segurar a criança, em razão de a mesma ter ficado extremamente agitada e nervosa ao colocarem a máscara da anestesia inalatória no seu rosto.

Nos registros dos diários de campo, verificou-se que apenas uma criança não se distraiu com os brinquedos disponibilizados na sala de pré-indução. Essa criança tinha 11 anos, o que pode sugerir que devem ser utilizadas novas formas de descontração para pacientes nessa faixa etária. Um método 
que pode ser empregado para reduzir a ansiedade de pacientes pediátricos, fácil e que poupa tempo, é o uso de intervenções pelo tablet ${ }^{15}$. O uso desse equipamento foi demonstrado ser superior à aplicação de midazolam, no que se refere à redução da ansiedade das crianças, com idade entre 1 e 11 anos, no momento da separação dos pais e durante a indução anestésica ${ }^{16}$.

Ainda que uma mãe entrevistada tenha referido não ter gostado da experiência de participar da indução anestésica, a equipe interagiu bastante com ela e com a criança, conversando e entretendo ambas durante esse momento. Além disso, a mãe foi acompanhada até a saída pela equipe de enfermagem depois de encerrado o processo e orientada sobre os momentos pós-cirurgia. Alguns fatores que facilitam o aparecimento de ansiedade nos pais podem estar relacionados com personalidade, idade, grau de escolaridade, estado civil, profissão, experiências hospitalares anteriores, preocupação com a cirurgia e com a própria anestesia ${ }^{17}$.

Em outro estudo ${ }^{18}$, as mães participantes expressaram sentimentos como angústia, impotência, solidão, culpa, medo, tristeza e ansiedade. Autores ${ }^{12}$ reconhecem que a entrada na área de cirurgia é estressante na presença ou na ausência dos pais. Pode-se perceber, neste trabalho, que os resultados se assemelham aos dos estudos citados anteriormente $^{12,18}$, visto que os sujeitos de pesquisa manifestaram medo e ansiedade. Além disso, foi possível verificar que, mesmo sendo o processo anestésico-cirúrgico desafiador, ocorrendo sentimentos negativos, as mães preferem participar desses momentos.

Os sujeitos E1 e E5 manifestaram sentimentos semelhantes no que se refere ao ato da anestesia e de não saber como a criança responderia. No entanto, o sujeito E1 relatou não ter sido uma experiência boa. O estresse dos pais pode interferir na habilidade de responder às necessidades emocionais da criança como, por exemplo, na capacidade de ajudá-la a criar estratégias para gerenciar esses sentimentos na hospitalização. Quando os pais são calmos e estão presentes contribuem na cooperação dos rebentos durante a realização dos procedimentos ${ }^{6}$. Sentimentos negativos podem fazer parte desse processo, visto que os procedimentos cirúrgicos envolvem alguns riscos, mas não tornam a experiência de participar da indução anestésica algo negativo.

Em estudo ${ }^{19}$ realizado na cidade de Porto, em Portugal, os pais acreditavam que a sua presença durante o período da indução e na SRPA diminuiu a ansiedade e trouxe maior conforto e segurança para a criança. Em contrapartida, quando os pais foram questionados sobre a chegada das crianças na SRA, 42,9\% disseram que as crianças estavam agitadas. Os dados do estudo citado ${ }^{19}$ divergem da presente pesquisa, em que os sujeitos expressaram tranquilidade em suas falas.

Durante a coleta de dados, percebeu-se dificuldade em realizar entrevistas com maior profundidade, visto que as mães estavam vivenciando um momento de razoável tensão, com concentração e estresses voltados para o contexto situacional do procedimento anestésico-cirúrgico pelo qual seus filhos estavam passando, o que trouxe pouco envolvimento entre entrevistado e entrevistador. É compreensível que isso ocorra em uma situação de saúde envolvendo criança e acompanhante, quando a atenção está voltada ao evento propriamente dito, deixando em segundo plano outras situações que possam ocorrer no mesmo momento.

\section{CONSIDERAÇÕES FINAIS}

Esta pesquisa permitiu conhecer as percepções dos acompanhantes de crianças (sete mães) na indução anestésica e no despertar da anestesia. Na pré-indução, a manifestação de expressões de tranquilidade prevaleceu tanto nas crianças quanto nas mães. Sobre a indução anestésica, algumas mães relataram sentimentos negativos durante o procedimento anestésico-cirúrgico, mas, apesar disso, a experiência foi positiva, visto que foi possível acompanhar todo o processo e garantir apoio e tranquilidade à criança.

Ao identificar os sentimentos suscitados na SRPA, predominaram o alívio e a felicidade. Além disso, a maioria das crianças despertou tranquilamente da anestesia. As estratégias utilizadas pelas mães/acompanhantes foram dar amor e carinho, choro no momento em que a criança adormeceu. Destaca-se como suporte da mãe, o papel exercido pela circulante de sala.

O papel do enfermeiro do CC e da SRPA, comprometido e capaz para agir e acalmar no sentido de acolher as crianças e as mães, torna-se imprescindível, gerando formas de assistir e de prestar cuidados.

Deve-se ponderar sobre tornar o acompanhante um participante ativo do processo, trazendo segurança para a criança e maior satisfação para quem a acompanha, de modo a tornar a indução anestésica um momento de maior tranquilidade para todos, com vistas a um melhor despertar do paciente pediátrico. 


\section{REFERÊNCIAS}

1. Anastácio DS, Souza MI, Aquino LA. Humanização do cuidado à criança em unidade de recuperação pós-anestésica. Rev SOBECC. 2014;19(3):136-41. DOI: 10.4322/sobecc.2014.021

2. Descritores em Ciências da Saúde (DeCS) [Internet]. São Paulo: BIREME/OPAS/OMS; 2017 [acesso em 2017 out. 09]. Disponível em: http://decs.bvsalud.org

3. Stangler MI. Impacto da medicação pré-anestésica na ansiedade pré-operatória e no delírio pós-operatório de crianças submetidas à cirurgia ambulatorial [dissertação]. Porto Alegre: Universidade Federal do Rio Grande do Sul; 2011 [acesso em 2017 out 10]. Disponível em: http://hdl.handle.net/10183/30978

4. Brasil. Lei n॰ 8.069 , de 13 de julho de 1990. Dispõe sobre o Estatuto da Criança e do Adolescente e dá outras providências [Internet]. Brasília; 1990 [acesso em 2017 out 10]. Disponível em: http://www. planalto.gov.br/ccivil_03/leis/L8069.htm

5. Menezes S, Tomazinho LD. Presença de familiares durante a indução anestésica de crianças: revisão da literatura. Rev SOBECC. 2014;19(2):92-8.

6. DeMaso DR, Snell C. Promoting coping in children facing pediatric surgery. Semin Pediatr Surg [lnternet]. 2013 [acesso em 2017 out 10];22(3):1348. Disponível em: https://www.ncbi.nlm.nih.gov/pubmed/23870206

7. Bardin L. Análise de conteúdo. Lisboa: Edições 70; 2009.

8. Brasil. Conselho Nacional de Saúde. Resolução $n^{\circ} 466$, de 12 de dezembro de 2012. Diretrizes e normas regulamentadoras de pesquisas envolvendo seres humanos. Brasília; 2012.

9. Velhote $A B$, Bohomol E, Velhote MC. Reações do acompanhante diante dos procedimentos pré-operatórios em cirurgia pediátrica ambulatorial. Einstein 2016;14(3):403-7. DOI: 10.1590/S1679-45082016A03624

10. Sampaio CE, Ventura DS, Batista IF, Antunes TC. Sentimento dos acompanhantes de crianças submetidas a procedimentos cirúrgicos: vivências no perioperatório. Rev Min Enferm. [Internet]. 2009 [acesso em 2017 out 10];13(4):588-64. Disponível em: http://www.reme.org. br/artigo/detalhes/224

11. Schneider CM, Medeiros LG. Criança hospitalizada e o impacto emocional gerado nos pais. Rev Unoesc Ciência [Internet]. 2011 [acesso em 2017 out 10];2(2):140-54. Disponível em: https://editora. unoesc.edu.br/index.php/achs/article/viewFile/741/pdf_216

12. Sadeghi A, Khaleghnejad TA, Mahdavi A, Salarian S, Razavi SS. Impact of parental presence during induction of anesthesia on anxiety level among pediatric patients and their parents: a randomized clinical trial. Neuropsychiatr Dis Treat [Internet]. 2017 [acesso em 2017 out 10];12:3237-41. Available at: https://www.ncbi.nlm.nih.gov/ pubmed/28260897

13. Kruger P, Rosen D. Parental presence at induction of anesthesia is feasible with minimal preparation and resources. Can J Anaesth [Internet]. 2016 [acesso em 2017 out 10];63(10):1207-8. Available at: https://www.ncbi.nlm.nih.gov/pubmed/27491958

14. Soliveres J, Sánchez A, Balaguer J, Estruch M, Sánchez J, Solaz C. Efectos de la presencia paterna en quirófano sobre la calidad de la inducción anestésica y agitación postoperatoria en niños. Rev Esp Anestesiol Reanim [Internet]. 2011 [acesso em 2017 out 10];58(8):472-6. Disponível em: http://www.elsevier.es/es-revistarevista-espanola-anestesiologia-reanimacion-344-articulo-efectospresencia-paterna-quirofano-sobre-S0034935611701219

15. Marechal C, Berthiller J, Tosetti S, Cogniat B, Desombres H, Bouvet $\mathrm{L}$, et al. Children and parental anxiolysis in paediatric ambulatory surgery: a randomized controlled study comparing $0.3 \mathrm{mg} \mathrm{kg}-1$ midazolam to tablet computer based interactive distraction. $\mathrm{Br} \mathrm{J}$ Anaesth [Internet]. 2017 [acesso em 2017 out 10];118(2):247-53. Available at: https://www.ncbi.nlm.nih.gov/pubmed/28100529

16. Seiden SC, McMullan S, Sequera-Ramos L, De Oliveira-Júnior GS, Roth A, Rosenblatt A, et al. Tablet-based interactive distraction (TBID) vs. oral midazolam to minimize perioperative anxiety in pediatric patients: a noninferiority randomized trial. Paediatr Anaesth [Internet]. 2014 [acesso em 2017 out 10];24(12):1217-23. Available at: https:// www.ncbi.nlm.nih.gov/pubmed/25040433

17. Ávila FR, Haro JM, Méndez NG. La ansiedad de los padres incrementa la ansiedade preoperatoria em el paciente pediátrico cuando este va a somerterse a cirurgia ambulatoria. Rev Esp Anestesiol Reanim [Internet]. 2012 [acesso em 2017 out 10];59(2):83-90. Disponível em: http://www.elsevier.es/es-revista-revista-espanolaanestesiologia-reanimacion-344-articulo-la-ansiedad-los-padresincrementa-S0034935612000515

18. Pavão TL, Montalvão TC. Mães acompanhantes de crianças cardiopatas: repercussões emocionais durante a hospitalização. Rev Psicol Saúde [Internet]. 2016 [acesso em 2017 out 10];8(2):67-82. Disponível em: http://pepsic.bvsalud.org/scielo. php?script=sci_arttext\&pid=S2177-093X2016000200006\&lng=pt

19. Barros F, Lages N, Lopez M, Pereira S. Ansiedade e grau de satisfação em anestesia pediátrica. Rev SPA [Internet]. 2005 [acesso em 2017 out 10];14(4):14-23. Disponível em: http://www.spanestesiologia. pt/wp-content/uploads/2008/11/14-4-artigo2.pdf 